\title{
Brincar no recreio escolar: ouvindo crianças dos anos iniciais do Ensino Fundamental
}

\author{
Andressa de Oliveira Martins ${ }^{1}$ \\ Fernando Donizete Alves ${ }^{2}$ \\ Aline Sommerhalder ${ }^{3}$
}

\begin{abstract}
Resumo
O objetivo deste estudo foi identificar jogos e brincadeiras vivenciados pelas crianças, assim como compreender os processos educativos desencadeados por essa prática social no contexto do recreio escolar, em uma escola pública de São Carlos/SP, que atende aos anos iniciais do Ensino Fundamental. Foram realizadas oito inserções em observação participante, com registros em diários de campo, no horário do recreio escolar, focando a prática social do brincar de um grupo de 13 crianças com idade entre seis e 11 anos. Os dados revelaram que o recreio escolar se constituiu em um rico espaço de experiências e aprendizagens das crianças, no que diz respeito ao repertório de jogos e brincadeiras e às interações entre as crianças e entre elas e adultos, no contexto dessas atividades lúdicas. Destacamos a necessidade de valorização do brincar no tempo e no espaço do recreio escolar, para a aprendizagem da criança e para sua articulação com as práticas pedagógicas.
\end{abstract}

Palavras-chave: criança; brincar; recreio escolar; Ensino Fundamental.

\footnotetext{
1 Mestranda em Educação pela Universidade Federal de São Carlos (UFSCar). Membro do Grupo de Estudos e Pesquisas sobre Processos Educativos de Crianças/CNPq.

2 Doutor em Educação Escolar pela Faculdade de Ciências e Letras da Universidade Estadual Paulista Júlio de Mesquita Filho (UNESP). Professor do Programa de Pós-graduação em Educação e do Departamento de Educação Física e Motricidade Humana da Universidade Federal de São Carlos (UFSCar). Coordenador do Núcleo de Estudos e Pesquisas sobre Educação Física Infantil - NEPEFI (CNPq).

3 Doutora em Educação Escolar pela Faculdade de Ciências e Letras da Universidade Estadual Paulista Júlio de Mesquita Filho (UNESP). Professora do Programa de Pós-graduação em Educação e do Departamento de Teorias e Práticas Pedagógicas da Universidade Federal de São Carlos (UFSCar). Coordenadora do Grupo de Estudos e Pesquisas sobre Processos Educativos de Crianças/CNPq.
} 


\title{
Playing at playtime: listening to children in the early years of elementary school
}

\begin{abstract}
The goal was to identify games and play experienced by children as well as understand the educational processes triggered by this social practice in the context of the playtime in a public school in São Carlos / SP / BR that meets the early years of elementary school. Were performed eight insertions in participant observation with records in field diaries in the playtime focusing on the social practice of play of a group of 13 children aged between six and 11. The data revealed that the playtime constituted a rich space of experiences and learning of children with regard to the repertoire of games and play and the interactions between children and between them and adults in the context of these playful activities. We emphasize the need of recognize the importance of play and playtime for learning of children and its articulation with the pedagogical practices.
\end{abstract}

Keywords: child; play; playtime; Elementary School.

\section{Introdução}

O recreio escolar, por vezes, é compreendido como espaço de intervalo de aulas (de distração e diversão), momento de gasto de energia, passatempo e descanso mental para as crianças. Nessa direção, momentos de convivência entre as crianças no recreio escolar podem ser equivocadamente compreendidos como apenas espaços e tempos que resultam em oportunidades de relaxamento, distração e descontração para as crianças, em que os processos de ensino e de aprendizagem ficam em segundo plano, ou mesmo não ocorrem.

Na contramão dessa concepção, que marca de modo pejorativo o tempo e o espaço do recreio escolar, compreendemo-lo como ambiente de encontro de diferentes pessoas (crianças e adultos), que possuem diferentes experiências culturais, pertencimentos sociais 
e diferentes repertórios de aprendizagens. O momento do recreio favorece aprendizagens e o desenvolvimento das crianças, por meio do convívio e da interação entre elas e delas com os adultos (inspetores, professores, gestores etc.). Sendo assim, conhecer esse ambiente pode oferecer elementos importantes aos professores sobre as crianças, seus saberes, contextos culturais e conhecimentos, para além dos contornos pedagógicos das salas de aula. E, dessa maneira, enriquecer suas práticas pedagógicas e, consequentemente, o processo de ensino e de aprendizagem.

Entre as diversas práticas sociais constituídas pelas crianças no contexto do recreio escolar, os jogos e as brincadeiras ocupam grande parte do tempo e do espaço. O recreio lhes possibilita um brincar com maior liberdade e autonomia, uma vez que a interferência adulta é pequena e, na maioria das vezes, com a intencionalidade de lembrar às crianças aquilo que elas não podem fazer, do ponto de vista das regras que regem esses tempo e espaço escolares. E é necessário que essas regras existam. Mas o ponto de nossas inquietações não é esse, e sim do que elas brincam, como organizam suas brincadeiras e seus jogos, o que ensinam e aprendem no interior dessa prática social constituída no recreio escolar.

Nessa direção, o objetivo deste estudo foi identificar jogos e brincadeiras vivenciados pelas crianças, assim como compreender os processos educativos desencadeados por essa prática social (o que ensinam e aprendem) no contexto do recreio escolar, em uma escola pública da cidade de São Carlos, interior do estado de São Paulo, Brasil, que atende aos anos iniciais do Ensino Fundamental.

Com o acesso ao $1^{\circ}$ ano do Ensino Fundamental com seis anos de idade (e, em alguns municípios, até com cinco anos), garantido pela Lei $\mathrm{n}^{\circ} 11274$, de 06 de fevereiro de 2006, inaugurou-se uma discussão sobre o Ensino Fundamental e a preservação das infâncias, incluindo-se, nessa discussão, a questão do direito de brincar das crianças, em diferentes espaços e tempos escolares. Pesquisas recentes (ARELARO; JACOMINI; KLEIN, 2011; KISHIMOTO et al., 2011) mostram que o brincar é pouco presente nas escolas de Ensino Fundamental, continuando a ser pouco valorizado, mesmo com o ingresso de crianças com seis anos nas unidades 
escolares. Apontam essas pesquisadoras que é apenas incorporando e articulando o brincar ao currículo e às práticas cotidianas da escola que é possível construir outra escola de Ensino Fundamental, que respeite verdadeiramente os direitos das crianças que, atualmente, nela ingressam com seis anos de idade.

Não há dúvidas de que brincar é uma prática que enriquece e que deve estar cotidianamente presente nos processos de ensino e de aprendizagem de crianças, em contextos escolares e não escolares. Para que o brincar seja incorporado ao cotidiano das práticas escolares, é preciso, além de conhecê-lo, analisá-lo, contextualizado aos grupos que o realizam e integrado às práticas de educar e de cuidar das crianças de zero a 10 anos, com o objetivo de contribuir para o enriquecimento das aprendizagens relativas às linguagens curriculares e outras experiências advindas das diversas culturas (SOMMERHALDER; ALVES, 2011).

A aproximação com a cultura lúdica, que se desenrola no recreio escolar, é fundamental para a promoção de uma prática pedagógica mais sensível, na medida em que pode corroborar uma melhor articulação entre os saberes e os conhecimentos produzidos e reproduzidos pelas crianças em suas brincadeiras e seus jogos, além da intencionalidade educativo-pedagógica do professor, e, numa perspectiva mais ampla, da própria escola.

\section{O brincar como prática social}

Em diferentes regiões do Brasil, assim como em vários cantos do mundo, as manifestações lúdicas são diversas e retratam várias realidades e culturas, sendo (re)construídas também a partir das relações humanas dos grupos ou das pessoas brincantes.

Brougère (2011) argumenta que a cultura lúdica, como qualquer cultura, é produzida pelos indivíduos que dela participam. A criança adquire, constrói sua cultura lúdica brincando. Representa o conjunto de sua experiência lúdica acumulada, desde as primeiras brincadeiras de bebê. Essa experiência é adquirida pela participação em jogos e brincadeiras com os companheiros, pela observação de outras, pela 
manipulação cada vez maior de objetos de jogos/brincadeiras.

Brougère (2003) destaca que as regras dos jogos de determinada sociedade compõem a cultura lúdica dessa sociedade, e as regras que um indivíduo conhece compõem sua própria cultura lúdica. O jogo e as brincadeiras são os lugares de construções da cultura lúdica. São processos culturais muito ricos.

Compreendemos que brincar é uma experiência relacional, intersubjetiva, expressa; (re)constrói culturas; é uma prática humana em que cada brincante também se constitui e se educa nas relações vividas com o outro. É, portanto, uma prática social, uma linguagem que possibilita a interação das crianças entre si e também com as demais pessoas (por exemplo, com os adultos) que participam da brincadeira. No brincar, ocorre a interação com a realidade, com o outro e com os diferentes símbolos, signos, costumes e valores que constituem as culturas.

Por prática social, compartilhamos ainda as ideias de Oliveira et al.:

Práticas Sociais decorrem e geram interações entre os indivíduos e entre eles e os ambientes natural, social, cultural em que vivem. Desenvolvem-se no interior de grupos de instituições, com o propósito de produzir bens, transmitir valores, significados, ensinar a viver e a controlar o viver, enfim, manter a sobrevivência material e simbólica das sociedades humanas. (OLIVEIRA et al., 2014, p. 33).

Apontam esses pesquisadores que as práticas sociais são construídas em relações humanas estabelecidas em um contexto de interações, cujas pessoas envolvidas nele se inserem por diversas motivações e objetivos. Dentre esses objetivos, podemos apontar a transmissão de conhecimentos, de valores, de tradições, a garantia de direitos culturais, sociais, políticos, a valorização de culturas etc. (OLIVEIRA et al., 2014). No campo escolar, as práticas sociais são múltiplas; não se realizam apenas em salas de aula, mas em tempos e espaços diversos, como no parque, no recreio, no refeitório etc.

Compreendemos o brincar/jogar como uma prática social, na medida que decorre de e gera interações entre as crianças, entre as crianças e os 
adultos, e entre elas e o ambiente natural, social, cultural em que vivem. Desenvolve-se no interior de grupos (como é o caso das crianças que se reúnem para jogar e/ou brincar), com a intencionalidade de produzir bens, de transmitir valores, significados.

Entender o brincar e/ou jogar como uma prática social, situada em um dado contexto social, histórico, cultural e político, implica considerar que as experiências lúdicas promovem, sobretudo, a formação para a vida, não devendo ser vistas meramente como instrumentos cujo objetivo é a transmissão ou a apropriação de alguma informação ou conteúdo. Na prática social de brincar, há processos educativos que são produzidos, desencadeados, valorizados, ensinados e aprendidos pelas crianças que estão brincando, com suas diversas percepções sobre a realidade, suas fantasias, suas criações, suas ações, a partir das relações intersubjetivas por elas estabelecidas. Trazem consigo saberes e conhecimentos, valores e posturas que compartilham com os parceiros de jogo e de brincadeiras. Nessa troca, novos saberes e conhecimentos são construídos sobre si próprias, sobre a coletividade, sobre a realidade em que vivem.

No brincar, produz-se, transmite-se, apropria-se, troca-se e recriase conhecimentos e saberes. Brincar é um fundamento da experiência cultural (SOMMERHALDER; ALVES, 2011). Por meio do brincar, a criança aprende e constrói conhecimentos, saberes; ela explora, inventa, experimenta, cria, reconhece valores e atitudes, apropria-se de regras, estabelece laços afetivos, forma-se para a vida; enfim, humaniza-se. De acordo com Sommerhalder e Alves (2011), a brincadeira proporciona o conviver e a formação humana, uma vez que o ser humano se constrói também nessa experiência humana.

Brougère (2011) também destaca que o brincar é um espaço de criação cultural por excelência; por meio do brincar e do jogar, a criança adentra no universo da cultura. Nessa direção, Kishimoto (2010) aponta que a brincadeira é uma ferramenta que auxilia na aprendizagem e no desenvolvimento da criança, uma vez que, por meio da brincadeira, a criança ensina e aprende diferentes regras, habilidades e linguagens.

É importante porque dá o poder à criança para tomar decisões, expressar sentimentos e valores, conhecer a si, os outros e o 
mundo, repetir ações prazerosas, partilhar brincadeiras com o outro, expressar sua individualidade e identidade, explorar o mundo dos objetos, das pessoas, da natureza e da cultura para compreendê-lo, usar o corpo, os sentidos, os movimentos, as várias linguagens para experimentar situações que lhe chamam a atenção, solucionar problemas e criar. (KISHIMOTO, 2010, p. 1).

No brincar, a criança tem a oportunidade de ensinar e de aprender com o outro; é um rico espaço de aprendizagem para a criança que proporciona a educação para a vida (SOMMERHALDER; ALVES, 2011). Esses autores destacam que a brincadeira gera diferentes processos educativos, que se desencadeiam do convívio entre as crianças. Esses processos educativos são formativos, pois possibilitam que a criança conheça a si mesmo, o outro e as culturas. Ao brincar, a criança aprende a compartilhar, a ceder, a ganhar e a perder; aprende, acima de tudo, a conviver com o outro e com o grupo, criando relações de respeito, de parceria e de amizade: "Há uma 'significância' na atitude lúdica, pois quem brinca diz alguma coisa e esse dito está repleto de conteúdos da existência humana." (PEREIRA, 2001, p. 89).

Pensando na educação escolar, Mascioli (2010) aponta que, nas escolas, as crianças têm pouco espaço para produzirem sua própria cultura brincante, uma vez que, nesse espaço, os jogos e as brincadeiras assumem função "pedagogizante". A autora destaca que o brincar vai sendo cada vez mais retirado do cotidiano das crianças, tornando-se algo restrito a determinados horários e espaços, como no caso do recreio escolar. Nos anos iniciais do Ensino Fundamental, Sommerhalder e Alves (2011) discutem que as brincadeiras deixam de fazer parte da rotina escolar, pois brincar é compreendido como uma atividade de passatempo e diversão, sem relação com os processos de ensinar e de aprender da criança distanciando-a, assim, do desenvolvimento humano. A ideia de que a educação escolar exige sistematização e racionalidade é incompatível com a ludicidade.

Considerar o brincar da criança como meio para a aprendizagem é considerar a criança enquanto produtora de saberes, reconhecendo que ela está em constante processo de aprendizagem, por meio das diferentes práticas sociais que participa, como o brincar. 
Nesse contexto, Borba (2009) ressalta que brincar é uma prática desvalorizada socialmente. Não se reconhece que essa prática gera processos educativos; assim, a brincadeira ainda é, muitas vezes, vista como separada dos processos de ensinar e de aprender da criança, sendo compreendida como uma atividade não séria.

\section{Caminho metodológico}

Esta investigação caracterizou-se como uma pesquisa de abordagem qualitativa, com a intenção de buscar uma compreensão mais detalhada dos significados e das características apresentadas pelos participantes da pesquisa (BOGDAN; BIKLEN, 1994). Nesse caso, as crianças em contextos de brincadeiras e de jogos. Tomamos como perspectiva um fazer pesquisa com as crianças, e não sobre ou para elas. Portanto, entendendo-as enquanto sujeitos, e não apenas como objetos de pesquisa, o que "reflete uma preocupação direta em capturar as vozes infantis, suas perspectivas, seus interesses e direitos como cidadãos" (CORSARO, 2011, p. 57).

O presente estudo foi desenvolvido em uma escola pública que atende aos anos iniciais do Ensino Fundamental ( $1^{\circ}$ ao $5^{\circ}$ ano $)$, localizada no município de São Carlos, interior do estado de São Paulo, Brasil, onde foi acompanhado o recreio escolar das crianças matriculadas no período vespertino. O horário do recreio era de 14h50min. às 15h20min. Participaram da pesquisa 13 crianças com idade entre seis e 11 anos, matriculadas em turmas de anos iniciais do Ensino Fundamental.

A técnica usada para a coleta de dados foi a observação participante. Cruz Neto (2001) esclarece que essa técnica acontece pelo contato direto do pesquisador com o fenômeno que será observado, tomando a realidade dos participantes de pesquisa em seus próprios contextos. Nessa técnica, o pesquisador se insere no contexto da pesquisa, estabelecendo relações com os participantes da pesquisa.

A importância dessa técnica reside no fato de podermos captar uma variedade de situações ou fenômenos que não são obtidos por meio de perguntas, uma vez que, observados diretamente na própria realidade, transmitem o que há de mais importante e evasivo na vida real (CRUZ NETO, 2001, p. 59-60). 
Sendo assim, foram realizadas inserções colaborativas, na perspectiva de produzir pesquisas com as crianças colaboradoras, e não sobre elas. Oliveira et al. (2014) indicam a importância do estabelecimento de relações de confiança e de interação com o grupo ou com as pessoas colaboradoras da pesquisa, de modo que as inserções busquem compreender, e não julgar, as realizações dos participantes da pesquisa.

Considerando a importância do conviver e do estar com as crianças, as inserções aconteceram duas vezes por semana, durante os meses de maio e junho de 2015, totalizando oito inserções de acompanhamento do recreio escolar. Coerente com a proposta de fazer uma inserção colaborativa, brincar com as crianças foi parte da postura e do ato de pesquisar. De acordo com Brandão (1981), a participação não se reduz a uma mera aproximação do pesquisador para conhecer o mundo que pesquisa, mas deve ser pautada em um processo de convivência e de interação com o grupo. Aqui, foi fundamental o movimento de abertura para escutar as crianças:

[...] escutar é dar a si próprio e aos outros um tempo para ouvir. Por trás de cada ato de escuta, há um desejo, uma emoção, uma abertura às diferenças, a valores e pontos de vista distintos. Por conseguinte, devemos escutar e dar valor às diferenças, aos pontos de vista dos outros, sejam homens, mulheres ou crianças, especialmente para lembrar que, por trás de cada ato de escuta, restam a criatividade e a interpretação de ambas as partes. (RINALDI, 2012, p. 209).

Procurou-se, ao longo das inserções, criar relações de convívio, de diálogo e de confiança com as crianças, buscando pertencimento ao grupo. Com o passar das inserções, as crianças foram criando vínculos e reconhecendo a parceria para as brincadeiras. O convite para brincar, feito pelas crianças, possibilitou-nos aproximar com mais profundidade da realidade investigada. Na pesquisa com crianças, segundo Silva, Barbosa e Kramer (2008), é fundamental ver e ouvir:

Ver: observar, construir o olhar, captar e procurar entender, reeducar o olho e a técnica. Ouvir: captar e procurar entender; escutar o que foi dito e o não dito, valorizar a narrativa, entender a história. Ver e ouvir são cruciais para que se possa compreender 
gestos, discursos e ações. Esse aprender de novo a ver e ouvir (a estar lá e estar afastado; a participar e anotar; a interagir enquanto observa a interação) se alicerça na sensibilidade e na teoria e é produzida na investigação, mas é também um exercício que se enraíza na trajetória vivida no cotidiano (SILVA; BARBOSA; KRAMER, 2008, p. 86).

Utilizou-se o instrumento Diário de Campo para o registro dos dados (BOGDAN; BIKLEN, 1994). O Diário de Campo foi utilizado em todas as inserções de observação participante, e foram numerados de acordo com a sessão de coleta. A escrita dos diários foi realizada sempre no mesmo dia de cada inserção de observação participante, logo após a sua finalização. O processo de organização e de análise dos dados correu na perspectiva qualitativa, à luz do referencial teórico escolhido.

O desenvolvimento do estudo respeitou os cuidados éticos, de acordo com a Resolução n ${ }^{\circ}$ 466/2012, e foram utilizados nomes fictícios, escolhidos pelas próprias crianças.

\section{Criação de estratégias e resolução de problemas}

Para o presente texto, serão apresentados alguns dos resultados encontrados. Considerou-se que o recreio se constituiu em um espaço pedagógico muito rico para experiências e aprendizagens das crianças, desencadeando processos educativos que foram construídos nas interações que ocorreram entre crianças, e entre elas e os adultos, promovidas no brincar.

O recreio, do latim recreatio-onis, possui sentido na criação (CUNHA, 1997); é parte da rotina instituída pela escola e, portanto, precisa ser mais valorizado enquanto ambiente educativo-pedagógico. Mesmo sendo esse um momento instituído pela escola, as crianças se apropriam dele e o vivenciam de diferentes maneiras, constituindo diferentes práticas sociais. A partir das observações realizadas, brincar foi a principal prática social desenvolvida pelas crianças durante o recreio escolar. Esse brincar ocorreu de diferentes formas: 
Durante o recreio as crianças estão realizando diferentes brincadeiras: brincam de pega-pega (andando), amarelinha, esconde-esconde, jogos com as mãos (pedra, papel, tesoura; caminhão de laranja; adoleta etc.), batem cartinhas, brincam com brinquedos (Diário de Campo $\mathrm{n}^{\circ} \mathrm{I}$ ).

Nas experiências de brincar, as crianças produziram diversos processos educativos, seja no grupo, seja individualmente; assim:

Nos jogos e brincadeiras observados no dia de hoje, foi possível perceber que as crianças estabelecem relações de afeto, criam laços de amizade ou de inimizade, fazem escolhas (qual carta jogar, por quem torcer), criam e solucionam conflitos, incluem e excluem determinadas crianças, criam regras e reinventam essas regras de acordo com as necessidades e os desejos do grupo de brincantes. (Diário de Campo $\mathrm{n}^{\mathrm{O}} \mathrm{IV}$ ).

Nessa prática social, as crianças construíram conhecimentos não apenas de "conteúdos" das disciplinas escolares, mas também conhecimentos para a vida: aprenderam a se relacionar, a respeitarem umas às outras, a fazerem escolhas e a manifestarem preferências e interesses. Sobre isso, Oliveira et al. (2014) apontam que os conhecimentos que são construídos nas práticas sociais das quais participamos nos formam, e que essa formação ocorre em parceria, em colaboração com aqueles com que convivemos, uma vez que "participam pessoas com diferentes percepções e conhecimentos, em diferentes processos de trabalho e lazer, em diferentes espaços, escolares e não escolares." (OLIVEIRA et al., 2014, p. 35).

Durante o recreio, as crianças se relacionaram entre si em uma dinâmica em que aspectos como idades diferentes, gênero, classe social, religião e etnia não foram empecilho. Também buscaram ampliar seu núcleo de relações para além dos pequenos grupos de amizade, ou mesmo de turmas, ou seja, buscaram se relacionar com outras turmas, com as quais não conviviam diariamente em sala de aula.

Isso proporciona, conforme apontam Oliveira et al. (2014), múltiplas redes relacionais e múltiplas redes de construção de conhecimento, permitindo conhecer diferentes modos de ser, de pensar, de agir e, principalmente, diferentes modos de brincar, ampliando o repertório de 
apropriação e de produção de cultura lúdica infantil. Para os autores, "nestas relações de convívio amistoso, tenso, acolhedor, excludente, as pessoas se educam na sua humanidade para a cidadania negada, conquistada, assumida." (OLIVEIRA et al., 2014, p. 35).

As crianças colaboradoras do estudo se organizaram em diferentes grupos para brincar, a partir de amizades já existentes ou mesmo por tentativas ainda sutis e tímidas de novas parcerias; estas últimas, fomentadas por algumas crianças que convidaram outras para brincar, inicialmente, sem vínculo de amizade construído. Encontrar caminhos para lidar, por exemplo, com conflitos gerados por interesses diferentes nas brincadeiras, lidar com as regras da escola e a produção do brincar infantil (como não correr durante o recreio para não se machucar), tomar decisão coletiva sobre 'brincar de quê'? e criar diferentes estratégias individuais para o desenvolvimento de uma brincadeira que aconteceu em grupo foram outros processos educativos identificados nessa prática social de brincar, considerada como parte da cultura da infância.

[...] algumas crianças estão 'tirando' 2 ou 1, e perguntei do que elas iam brincar; uma das meninas me disse que iam brincar de pega-pega, então, considerando que é uma regra da escola não correr, eu perguntei: como vocês brincam de pega-pega se não pode correr? Ela me respondeu prontamente, dizendo que eles haviam mudado a brincadeira, que eles andavam rápido, e quem tinha que pegá-los ia andando bem devagar, mas que não podia trapacear. (Diário de Campo ${ }^{\circ} \mathrm{I}$ ).

Mais uma vez, questionei uma criança sobre como brincam de pega-pega, se não podem correr. Ela me explicou que é difícil, mas que tem que obedecer às regras do jogo, que tem que ser andando, e que quem está pegando tem que andar bem 'devagarzinho'. (Diário de Campo n III).

Esses trechos evidenciam que, dentro da escola, havia regras que precisavam ser respeitadas, até por razão de segurança das crianças (de modo que não se machucassem ao brincar). Assim, um grupo de crianças criou uma nova estratégia para lidar com a situação, o que exigiu que todos os que estavam inseridos naquele grupo seguissem essas regras, de modo que a brincadeira pudesse ser desenvolvida. Pensando nessa 
criação coletiva de estratégias entre as crianças que pertencem a um mesmo grupo, Borba (2009) aponta que as crianças criam, em parceria, estratégias para lidarem com determinadas situações e problemas que surgem, partilhando formas próprias de compreensão de mundo.

De acordo com essa autora, culturas da infância são formas de ação social contextualizadas, sendo uma construção coletiva das crianças frente aos espaços em que estão inseridas. “É engajando-se ativamente nessas estruturas e no esforço de compreendê-las que as crianças criam formas específicas de ação, reproduzindo, contornando ou até transformando as estruturas existentes." (BORBA, 2009, p. 144).

Com a inserção no grupo de crianças que "batiam cartinhas", anunciado por elas como "bater bafo", foi possível identificar como ocorreu a criação de estratégias nesse jogo. Mesmo diante das regras pré-existentes, necessárias para o desenvolvimento desse jogo, algumas crianças, no decorrer da prática, criaram estratégias para modificar (e "burlar") essas regras, sendo algumas delas em favorecimento próprio. Um exemplo disso ocorreu quando algumas crianças, de forma intencional, mas despercebidas pelos seus parceiros de jogo, passaram saliva na mão ou assopraram a mão para colar a carta (grude), facilitando que a mesma virasse.

Sendo uma linguagem, brincar expressa valores, costumes, condutas e hábitos do contexto social e cultural da criança, que também são transmitidos como processos educativos. "Ela brinca com o poder, com a vida, com a morte, com o proibido [...]" (SOMMERHALDER; ALVES, 2011, p. 20). No contexto de vivência cultural em uma sociedade competitiva, uma nova estratégia para vencer o jogo pode ser compreendida pelas crianças como algo justificável, mas que, no âmbito educativo, exige intervenção pedagógica, problematizando essa questão.

Um dos meninos, Nicolas, na hora do ímpar ou par, sempre esperava eu colocar o número primeiro, para depois ele colocar. Os outros garotos, ao verem isso, começaram a ficar bravos; disseram que ele estava 'trapaceando', que ele sempre faz isso, só para poder começar.

$[\ldots]$

Hoje, Nicolas também tentou "burlar", fazendo grude durante o 
jogo; todas as crianças diziam que havia sido grude, e ele negava. Observei algumas das estratégias que ele usa para conseguir virar a cartinha. Antes de bater, ele junta as duas mãos em forma de cone e "sopra" dentro delas, esquentando-a; assim, quando ele bate na cartinha, ela gruda com mais facilidade. (Diário de Campo $n^{\circ}$ IV).

Por outro lado, os resultados também revelaram que algumas estratégias de jogo foram criadas e aceitas por um coletivo de crianças, para facilitar o desenvolvimento do jogo, conforme retrata a cena:

Hoje, durante o intervalo do recreio, muitas crianças passaram pela mesa que estava no pátio da escola. Todas às vezes em que eu ia "bater cartinha", a minha mão grudava na carta; então, as crianças me sugeriram que eu esfregasse a mão na mesa, para tirar o suor. Jaqueline fazia isso o tempo todo, e a mesa começou a ficar manchada, com marcas de sujeira. Neymar dizia que isso estava acontecendo porque a mão dela estava suja. Jaqueline apenas dava risada. (Diário de Campo ${ }^{\circ} \mathrm{VI}$ ).

Sommerhalder e Alves (2011) apontam que é no "como se" da brincadeira que as crianças buscam alternativas para lidar com as dificuldades e/ou problemas que vão surgindo. Para compreender a criação coletiva de estratégias entre as crianças que pertencem a um mesmo grupo, os estudos de Borba (2009) examinam que:

Partilhando os mesmos espaços e tempos e o mesmo ordenamento social institucional, as crianças criam conjuntamente estratégias para lidar com a complexidade dos valores, conhecimentos, hábitos, artefatos que lhes são impostos e, dessa forma, partilham formas próprias de compreensão e de ação sobre o mundo. (BORBA, 2009, p. 145).

Ainda para essa autora, ao partilhar formas próprias de compreensão e de ação sobre o mundo, cria-se o pertencimento a esse grupo e ao mundo social e cultural. Assim, as práticas sociais, neste estudo em particular, o brincar permite a construção da pessoa e também da coletividade (OLIVEIRA et al., 2014).

Além das estratégias que as crianças criaram para o desenvolvimento de jogos e brincadeiras, outros processos educativos foram gerados a partir de estratégias construídas durante os momentos do lanche escolar, 
que ocorreram no recreio.

Giovana e Mariane logo me viram e disseram oi. Hoje, Giovana havia levado um iogurte de potinho e o tomava sem colher. Ela dividia também o iogurte com Mariane. Giovana me disse que encontrou um jeito de conseguir comer sem colher, tomando o iogurte, pois não havia levado colher, e, como o iogurte estava bem líquido, não precisava dela. (Diário de Campo $\mathrm{n}^{\circ} \mathrm{VII}$ ).

Como eu estava próxima à Mariane, ela me entregou um pacote de biscoitos e pediu para que eu a ajudasse a abri-lo. Era um pacote de biscoitos recheados de chocolate; a embalagem era transparente e muito difícil de abrir; não tinha aquelas famosas "fitinhas vermelhas" de puxar. Tentei abrir de várias maneiras, mas eu também não consegui. Giovana, que estava observando a situação, disse para Mariane que ela deveria rasgar a embalagem com o dente, que aquela embalagem de biscoitos era difícil mesmo de abrir, e que ela sempre fazia desse modo. (Diário de Campo n ${ }^{\circ} \mathrm{V}$ ).

Ao se depararem com diferentes desafios e possíveis situações problemáticas, as crianças criaram novas estratégias e, com isso, novas formas para lidar com as situações. No primeiro trecho do Diário, a fala de Giovana revelou que, ao ficar sem a colher, após observar o estado líquido do iogurte, ela criou uma estratégia para conseguir apreciar o alimento.

No segundo trecho, considerando o comentário de Giovana, compreende-se que ela já lidou com essa situação em outro momento; assim, compartilhou com a colega uma forma de resolução do problema: "abrir com o dente". Ao ver que sua amiga Mariane estava passando pelo mesmo problema, apontou-lhe um jeito de fazer, uma vez que Giovana já tinha um saber sobre aquele objeto, a embalagem de biscoitos. Nessa situação, Giovana compartilhou com Mariane saberes que provavelmente havia adquirido em outro contexto.

Com isso, ao se depararem com diferentes desafios ao brincar, as crianças criaram novas estratégias. Sobre isso, Oliveira et al. (2014) apontam que as pessoas relacionam o aprendido em uma prática social com o que estão aprendendo em outros espaços, e usam dessas aprendizagens para construírem outros conhecimentos. A brincadeira "é um espaço em que a criança pode experimentar, descobrir, criar e 
recriar experiências e saberes sobre si própria e sobre o mundo que as cerca." (SOMMERHALDER; ALVES, 2011, p. 20).

Ao se verem desafiadas, as crianças construíram estratégias de forma coletiva ou individual; essas estratégias podem ser novas ou que já foram utilizadas em outros contextos ou momentos de brincadeira. $\mathrm{O}$ brincar necessita de habilidades, de encontros e de acordos entre aqueles que aceitam participar, uma vez que:

[...] a atitude de quem brinca não é de simples prazer e de fácil contentamento, é um viver a tensão das escolhas, dos conflitos, dos limites, do fazer e desfazer das ações e imaginações em que o brincante experimenta o equilíbrio e o desiquilíbrio, o contraste e o semelhante, a união e a desunião. (PEREIRA, 2001, p. 90).

Brincar requer fazer escolhas, tomar decisões, desafiar o determinado, interagir, pois é nessa prática social que a criança aprende o significado e o sentido, por exemplo, da competição e da cooperação.

Esses resultados revelaram que algumas estratégias foram construídas e compartilhadas pelo grupo brincante de crianças, enquanto outras foram construções individuais, vistas como "quebra de regras". Essa decisão do compartilhado pelo grupo ou do instituído apenas por uma criança foi identificada a partir do acompanhamento dos acordos feitos por elas durante a brincadeira, pois "os rumos da brincadeira não estão dados a priori, ou seja, a criança não sabe de antemão os desdobramentos da brincadeira [...] e, é este não saber, este desconhecimento que a mantém brincando" (SOMMERHALDER; ALVES, 2011, p. 21).

\section{Aprendizagens necessárias para a inserção e a participação nas brincadeiras}

Brincar acontece em determinados espaço e tempo e se modifica de acordo com o grupo que o desenvolve, pois as crianças criam suas próprias regras mediante as situações que lhes são apresentadas, considerando que, "para existir o brincar precisa haver quem brinca, um 'objeto', um tempo, um espaço, e um conjunto de mecanismos que 'regulam' uma determinada ação." (PEREIRA, 2001, p. 90). 
Ao se inserir em um grupo de crianças para brincar, é preciso conhecer e respeitar alguns pressupostos básicos, como as regras e os acordos feitos pelo grupo de crianças, entre outros vários aspectos que apenas se é possível compreender e conhecer quando se está "brincando com", uma vez que brincar em coletivo "é uma atividade social dirigida pelas decisões internas daqueles que dizem sim ao ato de brincar e pelos acordos estabelecidos por aqueles que brincam." (PEREIRA, 2001, p. 90).

A inserção em um grupo de crianças que "batiam cartinhas" durante o recreio escolar possibilitou "sentir na pele" o modo como ocorreu a entrada de um novo parceiro/a na brincadeira, e como a cultura lúdica de um coletivo de crianças é transmitida e, assim, mantida viva:

Passei boa parte do recreio com as crianças que estavam "batendo cartas". Perguntei a uma das meninas que estava brincando como era a brincadeira e quais as regras. Ela me disse que cada um deveria colocar uma carta na mesa, assim, ficariam duas cartas; após tirar par ou ímpar, quem vencesse poderia "bater" primeiro na carta. Se o primeiro conseguisse virar as duas cartas, ele recuperava a sua carta e ganhava também a carta do colega; se não conseguisse, era a vez do outro. Pedi para que o grupo me ensinasse como deveria bater na carta. (Diário de Campo ${ }^{\circ}$ II).

Antes de se inserir de fato na brincadeira, é necessário conhecer as regras mínimas para o seu desenvolvimento. Nesse caso, algumas regras básicas foram compartilhadas pelas crianças com os novos integrantes da brincadeira. Sobre isso, Brougère (2011) aponta que se inserir na cultura lúdica infantil requer uma série de referências que permitam interpretar as atividades. Assim, essas referências são fundamentais para o brincar. Os resultados deste estudo revelaram que essas referências foram ensinadas por outros jogadores ao novo jogador.

Quando comecei a brincar com as crianças, não conseguia virar as cartas; nunca havia feito aquilo, nem quando criança. Um dos meninos que estava ao meu lado disse que eu não estava fazendo certo, que eu não podia deixar a mão tão aberta, e tentou me mostrar como fazer. Depois de tentar um pouco, sem sucesso, consegui virar algumas cartas, mas, como eu não tinha minhas próprias cartas, não participei por muito tempo da brincadeira. Fiquei observando, juntamente com algumas outras crianças que 
esperavam a sua vez de jogar. (Diário de Campo n ${ }^{\circ}$ II).

Uma das crianças disse que iria me ensinar como brincar, e então demonstrou como eu deveria fazer. O segredo não era bater com força na carta, mas sim bater com a parte certa da mão. Outra criança me disse que eu deveria bater com a parte mais "gordinha" da mão, perto do dedão. Disseram para eu tentar um pouco sozinha, sem valer na partida do jogo. Tentei algumas vezes e disse que já estava pronta; então, começaram a disputar uma partida para ver quem seria meu primeiro adversário. (Diário de Campo $\left.\mathrm{n}^{\mathrm{O}} \mathrm{III}\right)$.

Iniciei brincando com um menino que me ensinou muitas coisas da brincadeira. Ele me disse que, quando você bate na carta e ela cola na sua mão, isso se chama "grude", e que, se você conseguir virar a carta assim, você não pode pegar ela para você, pois é uma trapaça na regra do jogo. (Diário de Campo $\left.n^{\circ} \mathrm{III}\right)$.

As crianças constroem em parceria jeitos e maneiras de brincar; com isso, inventam e reinventam a cultura lúdica. Alves e Sommerhalder apontam que, "no brincar está presente a dimensão de risco, do prazer da surpresa e da curiosidade, numa aventura que convida constantemente o brincante a rever e a produzir" (ALVES; SOMMERHALDER, 2006, p. 130).

Sobre a inserção de um novo participante no jogo, os resultados deste estudo revelaram que esse é um processo que envolve o conhecimento de referências mínimas para a inserção nesse universo. Brincar de "bater cartinhas" requer o conhecimento de uma estrutura pré-existente do jogo e de suas regras. Kishimoto et al. (2011) apontam que, em todas as brincadeiras e jogos, existem regras, sejam implícitas ou explicitas. Sendo assim, as crianças compartilharam e criaram, juntas, também algumas regras no decorrer da brincadeira, tornando-se parceiras no brincar.

A inserção em um jogo foi acompanhada por diversos processos educativos, como a aprendizagem das regras, a aprendizagem de estratégias de jogo, a aprendizagem da convivência com o outro; a inserção de um novo jogador resultou na mobilização de todo o grupo de crianças, de modo a acolher e a integrar esse novo brincante no universo lúdico do momento.

Por meio dessa prática social de brincar, essas crianças compartilharam saberes, valores e tradições das brincadeiras, bem como produziram 
novos jeitos de brincar, transformando a própria cultura lúdica. Os resultados mostraram que brincar no recreio escolar promoveu diversas aprendizagens e a socialização das crianças.

\section{Considerações finais}

Brincar foi vivido por esse grupo de crianças como a principal prática social desenvolvida no recreio escolar. Nesses espaço e tempo, ficou muito evidente a interação das crianças entre si, explorando os brinquedos, os espaços, enfim, vivenciando seu brincar. A disponibilidade para brincar nos coloca outra temporalidade, que é diferente daquela que rege o recreio (o relógio). Estamos tratando de uma temporalidade psíquica, regida pelo imaginário e pelo simbólico. Nas palavras de Sartori, Alves e Sommerhalder, "como ela [a criança] faz daquele espaço um lugar para seu brincar e como são elaboradas suas construções lúdicas, que elementos participam e como" (SARTORI; ALVES; SOMMERHALDER, 2015, p. 405)

O fato de o brincar não ser uma prática social valorizada do ponto de vista social (não é produtivo) dificulta o reconhecimento de que essa prática é geradora de processos educativos. Emerique (2003) alerta que estamos imersos em uma cultura antilúdica, e os adultos são cada vez mais estimulados a deixarem para trás a própria infância. Por isso, brincar, para alguns adultos, é compreendido como sinônimo de algo não sério, de passatempo ou de perda de tempo, de coisa de criança, de pouco valor. Na escola, conclui esse autor, ouvimos com certa constância a frase "vamos parar de brincar que vai começar a aula!" (EMERIQUE, 2003 , p. 13), indicando uma forte cisão entre a "hora de brincar" e a "hora de estudar"; a "hora da diversão" e a "hora de atividades sérias". Desse modo, ainda no contexto escolar, brincar é entendido como uma atividade separada do processo de ensino e de aprendizagem de crianças.

A identificação e a compreensão de alguns processos educativos que decorrem da brincadeira no momento do recreio constituem importantes elementos para pensar a educação escolar de crianças e, em especial, as práticas pedagógicas em sala de aula.

Por meio do brincar, foi possível conhecermos o modo como as 
crianças estavam significando a realidade, pois, nas brincadeiras, as crianças anunciaram seus contextos de vida e de cultura, seus saberes e conhecimentos. Investigar processos educativos em práticas sociais de crianças do Ensino Fundamental é colaborativo nas discussões sobre as práticas pedagógicas que ocorrem em salas de aula, haja vista que o acompanhamento do brincar possibilitou o conhecimento mais aprofundado e verdadeiro sobre as crianças, a confirmação do interesse que elas possuem pelo brincar e, com isso, o modo como elas compreendem e representam a realidade. Nesse sentido, Freire (2003) ensina que não basta apenas ouvir e conhecer para que ocorra um processo de ensino compromissado e problematizador, mas que é indispensável partir do que as crianças trazem para ensinar-lhes o que ainda não sabem.

Considera-se a necessidade de outros estudos nesse campo, de modo a aprofundar os conhecimentos científicos sobre o brincar de crianças em recreios escolares, desvelando outros processos educativos decorrentes dessa prática social que possam ser colaborativos nas discussões sobre uma pedagogia para a infância, que tenha o lúdico como elemento integrador das práticas pedagógicas nos anos iniciais do Ensino Fundamental.

\section{Referências}

ALVES, F. D.; SOMMERHALDER, A. O brincar: linguagem da infância, língua do infantil. Revista Motriz, Rio Claro, SP, v. 12, n. 2, p. 125-132, mai./ago. 2006.

ARELARO, L.R.G.; JACOMINI, M.A.; KEIN, S.B. O ensino fundamental de 9 anos e o direito à educação. Educação e Pesquisa, São Paulo, v. 37, n. 1, p. 35-51, jan./abr. 2011.

BRASIL. Lei 11274, de 06 de fevereiro de 2006. Altera a redação dos art. 29, 30, 32 e 87 da Lei n. 9394 de 20 de dezembro de 1996, que estabelece as Diretrizes e Bases da Educação Nacional, dispondo sobre a duração de 9 (nove) anos para o ensino fundamental, com matrícula obrigatória 
a partir dos 6 (seis) anos de idade. Lei de Diretrizes e Bases da Educação Nacional. Brasília, DF, Atos do Poder Legislativo, 2006. Disponível em: <http://www6.senado.gov.br/legislacao/ListaPublicacoes. action?id=253755> . Acesso em: 10 mar. 2015.

BORBA, A. M. A participação social das crianças nos grupos de brincadeira: elementos para compreensão das culturas da infância. Revista Educação em Foco, Juiz de Fora, MG, v. 13, n. 2, p. 139-156, 2009.

BOGDAN, R.; BIKLEN, S. Investigação qualitativa em educação: uma introdução à teoria e aos métodos. Porto: Porto Editora, 1994.

BRANDÃO, C. R. Pesquisa participante. São Paulo: Brasiliense, 1981. BROUGÈRE, G. Jogo e educação. Porto Alegre: Artes Médicas, 2003.

A criança e a cultura lúdica. In: KISHIMOTO, T. M. (Org.). O brincar e suas teorias. São Paulo: Cengage Learning, 2011. p. 19-32.

CORSARO, W. A. Sociologia da infância. Porto Alegre: Artmed, 2011.

CRUZ NETO, O. O trabalho de campo como descoberta e criação. In: MINAYO, M. C. S (Org.). Pesquisa social: teoria, método e criatividade. Petrópolis, RJ: Vozes, 2001. p. 51-66.

CUNHA, A. G. Dicionário Etimológico Nova Fronteira da Língua Portuguesa. Rio de Janeiro: Nova Fronteira, 1997.

EMERIQUE, P. S. Brincaprende: dicas lúdicas para pais e professores. Campinas, SP: Papirus, 2003.

FREIRE, P. Professora sim, tia não: cartas a quem ousa ensinar. São Paulo: Olho d'Água, 2003.

KISHIMOTO, T. M. Brinquedos e brincadeiras na Educação Infantil. Brasília, DF: MEC, 2010. 
KISHIMOTO, T. M; PINAZZA; M. A.; MORGADO, R. F. C.; TOYOFUKI, K. R. Jogo e letramento: crianças de 6 anos no ensino fundamental. Educação e Pesquisa, São Paulo, v. 37, n. 1, p. 191-210, jan./abr. 2011.

MASCIOLI, S. A. Z. Brincar: um direito da infância e uma responsabilidade da escola. In: ANGOTTI, M. (Org,). Educação Infantil: para que, para quem e por quê? Campinas, SP: Editora Alínea, 2010. p. 105-116.

OLIVEIRA, M. W. et al. Processos educativos em práticas sociais: reflexões teóricas e metodológicas sobre pesquisa educacional em espaços sociais. In: OLIVEIRA, M. W.; SOUSA, F. R. (Orgs.). Processos educativos em práticas sociais: pesquisas em educação. São Carlos, SP: EdUFSCar, 2014. p. 29-46.

PEREIRA, E. T. Brincar, Brinquedo, Brincadeira, Jogo, Lúdico. Revista Presença Pedagógica, Belo Horizonte, v. 7, n. 38, p. 88-92, mar./abr. 2001.

RINALDI, C. Diálogos com Réggio Emília: escutar, investigar e aprender. São Paulo: Paz e Terra, 2012.

SARTORI, G. D.; ALVES, F. D.; SOMMERHALDER, A. A cultura lúdica infantil em parques públicos: qual o espaço e tempo para brincar? Educação Unisinos, São Leopoldo, RS, v. 19, n. 3, p. 401-408, set./dez. 2015.

SILVA, J. P.; BARBOSA, S. N. F.; KRAMER, S. Questões teóricometodológicas da pesquisa com crianças. In: CRUZ, S. H. V (Org.). A criança fala: a escuta de crianças em pesquisas. São Paulo: Cortez, 2008. p. 79-101.

SOMMERHALDER, A.; ALVES, F. D. Jogo e a educação da infância: muito prazer em aprender. Curitiba: CRV, 2011.

Recebido em 25/05/2016 Aprovado em 27/08/2016 